\title{
Design of a web-based GNSS data management system at HartRAO: preliminary results
}

\author{
Z.O. Mashaba \\ Centre for Geoinformation Science, Department of Geography, Geoinformatics and Meteorology, University of Pretoria, \\ South Africa
}

e-mail: u29132437@tuks.co.za

\section{W.L. Combrinck}

Hartebeesthoek Radio Astronomy Observatory, P O Box 443, Krugersdorp 1740, South Africa Centre for Geoinformation Science, Department of Geography, Geoinformatics and Meteorology, University of Pretoria, SA Programme of Land Surveying (Geomatics), University of KwaZulu-Natal, Durban, South Africa e-mail: ludwig@hartrao.ac.za

\section{J.O. Botai}

South Africa Weather Service, 442 Rigel Avenue South, Erasmusrand 0181, Pretoria, South Africa Centre for Geoinformation Science, Department of Geography, Geoinformatics and Meteorology, University of Pretoria, South Africa

e-mail: joel.botai@weathersa.co.za

\section{Munghemezulu}

Centre for Geoinformation Science, Department of Geography, Geoinformatics and Meteorology, University of Pretoria, SA Hartebeesthoek Radio Astronomy Observatory, P O Box 443, Krugersdorp 1740, South Africa

e-mail: cilence@hartrao.ac.za

\section{R.C. Botha}

Hartebeesthoek Radio Astronomy Observatory, P O Box 443, Krugersdorp 1740, South Africa e-mail: roelf@hartrao.ac.za

\section{(C) 2016 March Geological Society of South Africa}

\begin{abstract}
The Space Geodesy Programme of the Hartebeesthoek Radio Astronomy Observatory (HartRAO) is actively engaged in improving the African Earth and Ocean Monitoring Network (sub-project 1.1 of Inkaba yeAfrica) by installing geodetic, oceanographic and geophysics stations across the Sub-Saharan region and Southern ocean. This forms part of the drive to monitor different geophysical parameters via denser networks and with increasing accuracies, so as to better our understanding of the Earth system. The instruments being deployed include Global Navigation Satellite Systems (GNSS) stations, tide-gauges, seismic stations and meteorological units. There are four main space geodetic techniques collocated at HartRAO, making it a fiducial site in Africa. These techniques are GNSS, Satellite Laser Ranging (SLR), Very Long Baseline Interferometry (VLBI) and Doppler Orbitography and Radiopositioning Integrated by Satellite (DORIS). It is important to ensure that all the collected raw scientific data as well as the derived data products are accessible in a user-friendly manner. Additionally, a new data management system needs to be implemented at HartRAO in order to ensure data integrity. This paper focuses on the implementation of a GNSS data management system. The automated system for the pre-processing and post-processing of GNSS data and other derived products are presented. The data products are then visualized utilizing an interactive web-based map. These scientific products are important in understanding processes that occur on planet Earth such as plate motion, crustal deformation and weather patterns. The implementation of this data management system will facilitate the monitoring of these processes.
\end{abstract}




\section{Introduction}

The Hartebeesthoek Radio Astronomy Observatory (HartRAO), located North West of Johannesburg is the only observatory in Africa that has four collocated space geodetic techniques. These techniques are Satellite Laser Ranging (SLR), Global Navigation Satellite Systems (GNSS), Very Long Baseline Interferometry (VLBI) and the French Doppler Orbitography and Radiopositioning Integrated by Satellite (DORIS) system. The Lunar Laser Ranging (LLR) technique is currently under development. The observatory collaborates through various international organizations such as the International Laser Ranging Service (ILRS), the International VLBI Service for Geodesy and Astrometry (IVS) and the International GNSS Service (IGS), which provide astronomical and geodetic products and data to the scientific community and the public through their various analysis and data centres. The geodetic data are utilized by different scientific organizations such as the International Earth Rotation and Reference Systems Service (IERS). These data are used to compute scientific data products, for example; the International Celestial Reference System (ICRS), International Terrestrial Reference System (ITRS) and Earth Orientation Parameters (EOP) (Rothacher, 2003). The HartRAO observatory plays a crucial role in the estimation of geodetic and astronomical parameters, as outlined by Mayer et al. (2014).

The Space Geodesy Programme of HartRAO is actively engaged in improving the African Earth and Ocean Monitoring Network by installing various scientific stations across the SubSaharan region and Southern oceans. The geodetic instruments installed include a collocation of GNSS and tide-gauges along the coasts (e.g., Simons Town, Gough Island and Marion Island) and GNSS instrumentation in the Sub-Saharan regions (e.g., Namibia, Botswana, Zambia, South Africa). These are used for the African Geodetic Reference Frame (AFREF) project, ITRF, IGS, data products and other scientific projects (Combrinck, 2014). Geodetic data collected by the instruments are required to be available to the users in near-real time. Data latency is required to be minimal for near-real time data processing applications. Users require raw data, processed data as well as metadata for various applications and uses. These data are often downloaded automatically via scripts or web browsers. Therefore, it is important to make all the collected raw scientific data as well as the derived data products available in a user friendly manner, to both the scientific community and general public, for research and educational purposes.

A new data management system needs to be implemented at HartRAO to ensure minimal data latency. The data management system includes data products from the regional GNSS station network of which data are archived by HartRAO depicted in Figure 1. This network includes stations maintained by HartRAO and the IGS stations (for more information on these stations the reader is referred to Dow et al., 2008 or Beutler et al., 2008 and references therein). Data from the stations are required to be quality checked for errors, reworked into a specific format and stored for access timeously.

\section{GNSS Stations data archived at Hartebeesthoek Radio Astronomy Observatory (HartRAO)}

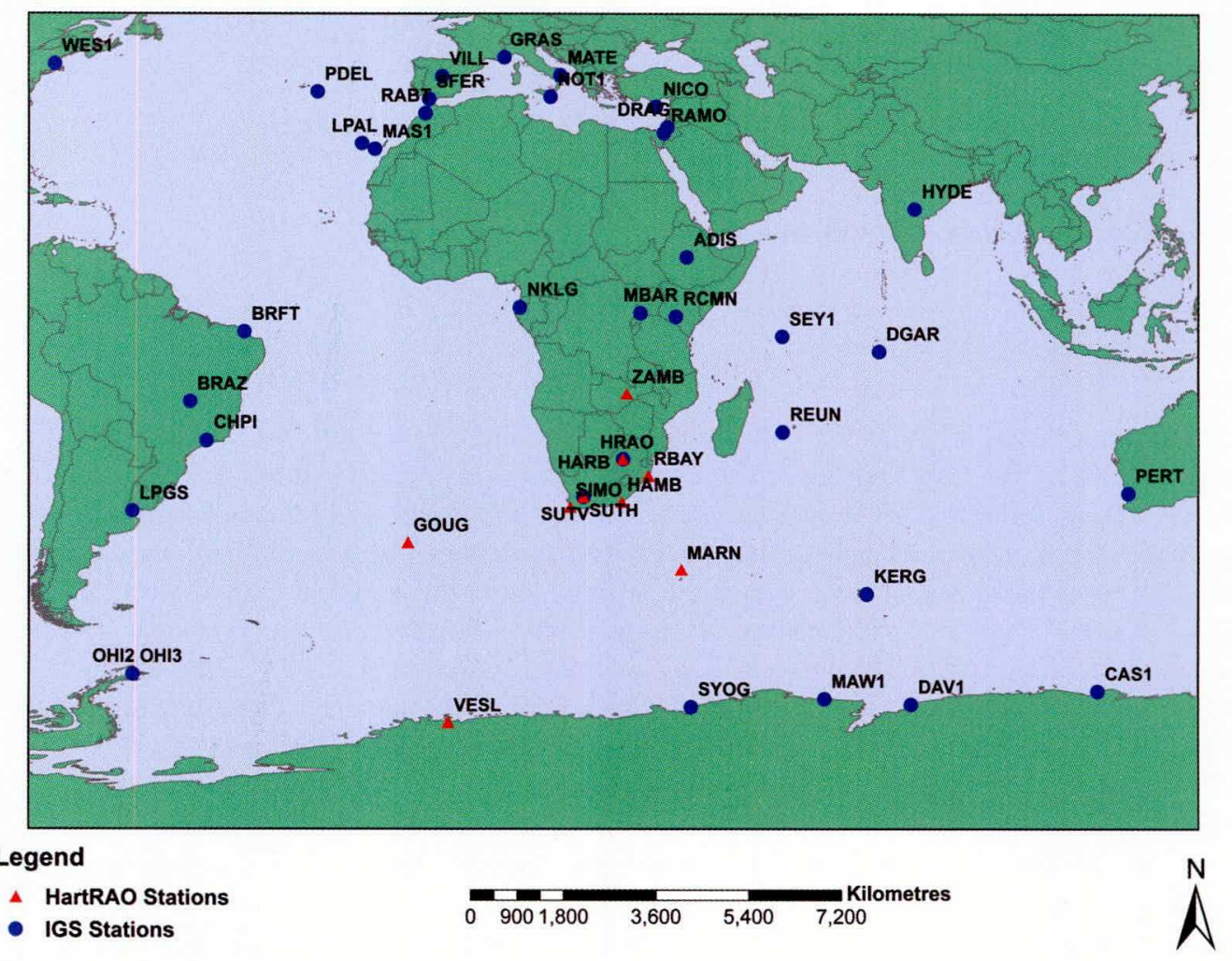

Figure 1. Regional GNSS station network data archived at HartRAO. 


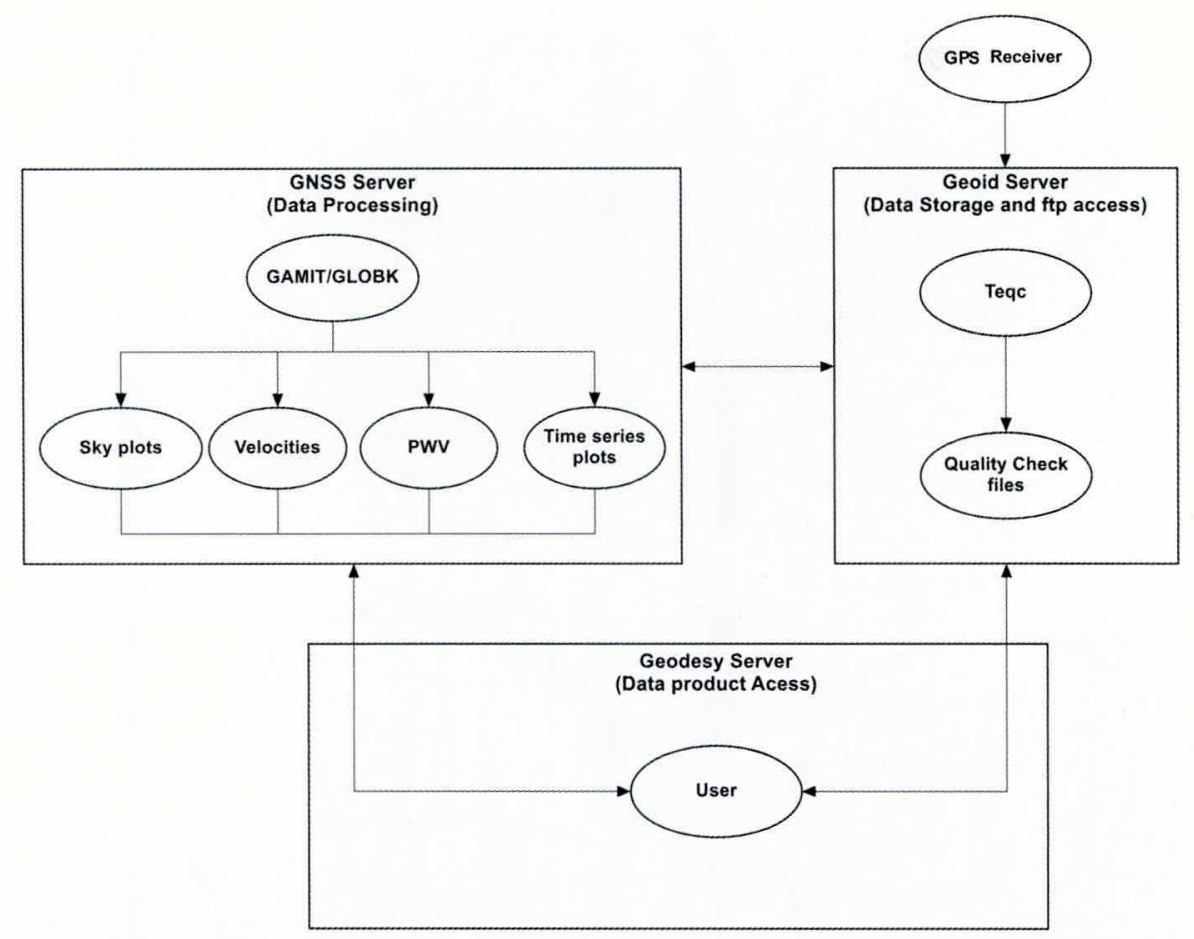

Figure 2. System architecture and the interaction between the three servers to produce data products created for the end user:

\section{Applications of the global navigation satellite systems technique}

The applications of GNSS include navigation and positioning for automobiles, airplanes, ships and cars. These navigation mediums are sometimes equipped with a moving map display that indicates the receiver's location on the centre of the map for route navigation (Someswar et al., 2013). In precision farming, Carrier Phase Differential GPS (CPDGPS) tracks the position of a vehicle within centimetres, which makes it an indispensable tool for controlling farm vehicles (O'Connor et al., 1996). For scientific use Argus and Heflin (1995) utilized geodetic data to estimate motion between tectonic plates and it was observed that the Pacific plate moves faster than the Eurasian and North American plates, as predicted by the NUVEL-1A model and supported by the VLBI data. Larson et al. (2010) applied the GPS technique to estimate the timing of volcanic eruptions. In the study, GPS time series was found to be accurate in depicting the time of eruption of the Kilauae volcano when compared to tiltmeter records. Recently, Gulala et al. (2013) monitored Continuous Operating Reference Stations (CORS) which are installed for the collection of geographic data and observed that the stations were moving consistently with the regional tectonic plate after trend component analyses, except for one station. Other applications of GNSS are in weather prediction model improvement where the bending of GNSS satellite signals by the atmosphere can be used to determine atmospheric conditions, for example air density, temperature, water vapour content and electron density (Hofmann-Wellenhof et al., 2008; Someswar et al., 2013). All these applications can benefit from improvements in accuracy, availability and integrity of GNSS data (Lechner and Baumann, 2000).

\section{Implementation strategy of the data management system}

There are three servers utilized for the development of the data management system at HartRAO, these are the Geoid server, the GNSS server and the Geodesy server. The servers are displayed in Figure 2 and these servers interact to make the final data and data products available to the end users. The Geoid server is a data storage repository that utilizes Linux as operating system. This server archives raw Receiver Independent Exchange Format (RINEX) data files from GNSS stations accessible with internet connectivity as well as other data servers managed by other organisations. These organisations include: the National Aeronautics and Space Administration (NASA), Crustal Dynamic Data Information System (CDDIS), Scripps Orbital and Permanent Array Center (SOPAC), University NAVstar Consortium (UNAVCO) and TrigNet (managed by Chief Directorate: National Geo-spatial Information, Department of Rural Development and Land Reform). The pre-processed data are also archived on the ftp site: ftp://geoid.hartrao.ac.za/rinex/ on the Geoid server. The data files are also processed using Teqc (Estey and Wier, 2014; Estey and Meertens, 1999) to derive the quality check files.

The GNSS server is hosted on a Linux machine to do processing of RINEX data files using the GAMIT/GLOBK 10.2 software (Herring et al., 2010) to obtain GNSS data products (time series plots, velocity field vectors and sky plots). The Met 4 data hosted at ftp://garner.ucsd.edu/pub/met/ are also collected and processed using the GAMIT/GLOBK 10.2 software. Meteorological parameters such as total zenith delay, wet zenith delay and IPWV can then be extracted. Finally, the Geodesy server hosts the website; this server is the front-end where users access the data of the station via the 

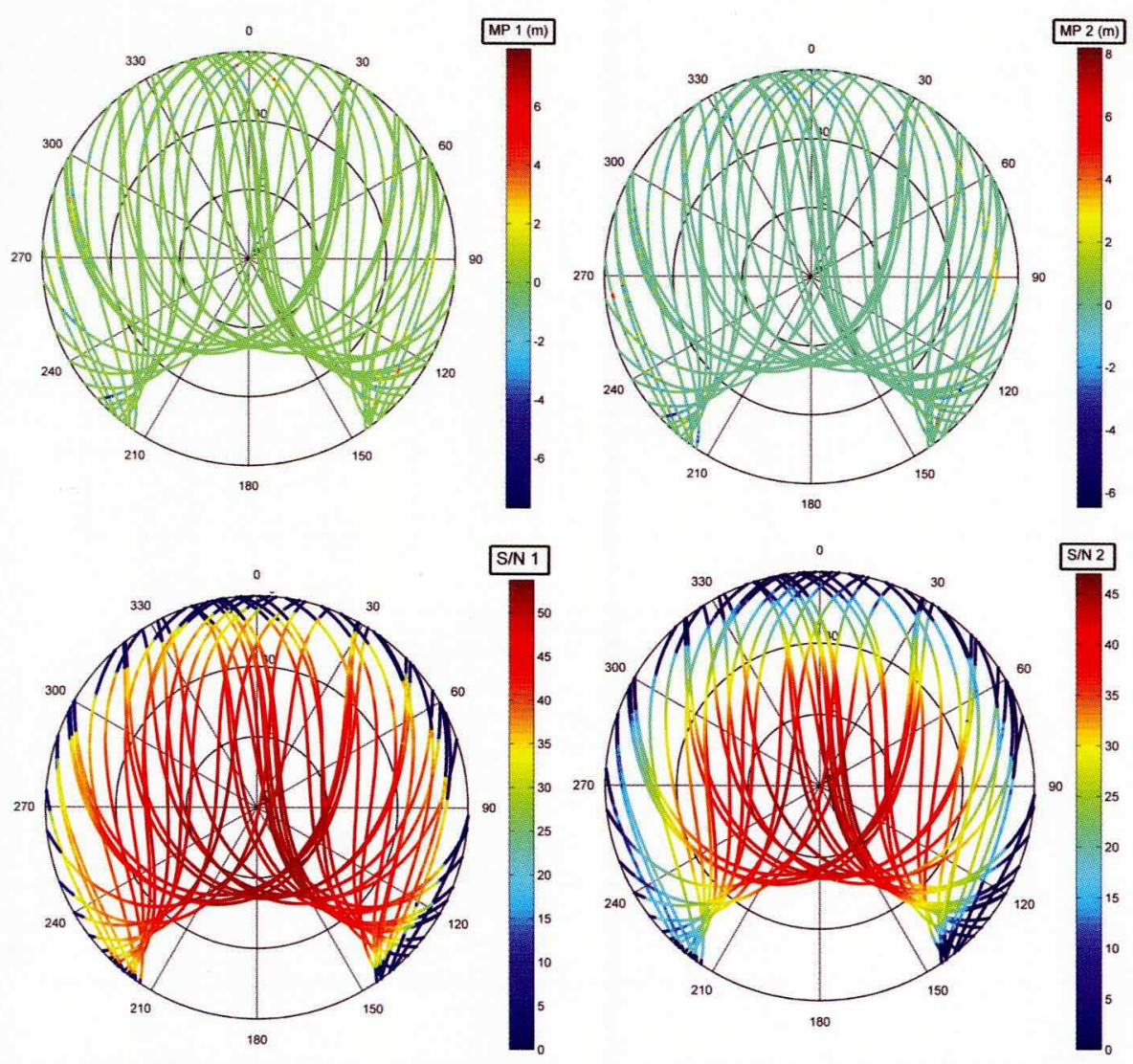

Figure 3. An example of sky plots from HRAO GPS station for the date 2015/01/10. The plot depicts data quality parameters i.e. multipath (MP1 and $M P 2)$ and signal-to-noise ratio (S/N 1 and S/N 2) for the full observational period of 24 hours. It is clear that the GPS observables have low quality at low elevations.

interactive web-map. The transfer of data files and data processing in the servers has been automated using Linux c-shell scripts.

\section{Current progress on GNSS data products}

The Earth is a complex dynamic system characterized by various geophysical processes that affect humankind. For example, tectonic plate motion induces earthquakes and volcanism, and variations in atmospheric parameters define weather patterns. Such processes require tools that can monitor the observed variations at both small and large scales. Space Geodesy has proven to have the capabilities to observe these geophysical processes with very high temporal, spatial and spectral resolutions through global networks of diverse equipment (VLBI, SLR, GNSS and DORIS), each making a valuable and unique contribution. The GNSS technology has been used as a multipurpose technique to study planet Earth with high accuracy levels, for example, detecting tectonic plate motion at millimetre accuracy, time transfer applications using GNSS (Defraigne et al., 2007) and studying atmospheric water vapour for applications in meteorological studies (Isioye et al., 2015).

Currently HartRAO is developing a GNSS data management system. This system is automated for the processing and preprocessing of GNSS data and other derived products such as positional time-series plots, Integrated Precipitable Water
Vapour (IPWV) values and quality check outputs. Finally, the interactive web-based data management system is derived which is not yet accessible publicly. This paper focuses on the current developments on GNSS data products.

\section{Sky plots}

The sky plots in Figure 3 depict the geometry of the satellite tracks in space during the 24 hour period of observation, this particular example was processed for HRAO GPS station for the date 2015/01/10. The plots can be used to check the visibility of satellites at a specific period. The outer circle (0 to 360 degrees) represents the satellite azimuth. The multipath (MP 1 and MP 2) and signal-to-noise ratio (S/N 1 and $\mathrm{S} / \mathrm{N} 2$ 2) parameters are plotted for $\mathrm{L} 1$ and $\mathrm{L} 2$ radio frequencies, which indicates the extent of noise levels at lower elevations. The multipath which occurs when satellite signals are reflected off nearby objects can vary from a few centimetres to metres, depending on the extent of objects around the GNSS antenna which cause noise in the GNSS data. The positional solution from GNSS is mainly affected by the multipath on site, hence, during processing, a cut-off angle varying from $5^{\circ}$ to $15^{\circ}$ is applied to improve the positional solution, which also depends on the number of observed GNSS satellites (El-Rabbany, 2002). However, Chew et al. (2013) have demonstrated the use of noisy signal to infer soil moisture, vegetated or bare soil around the GNSS site by 

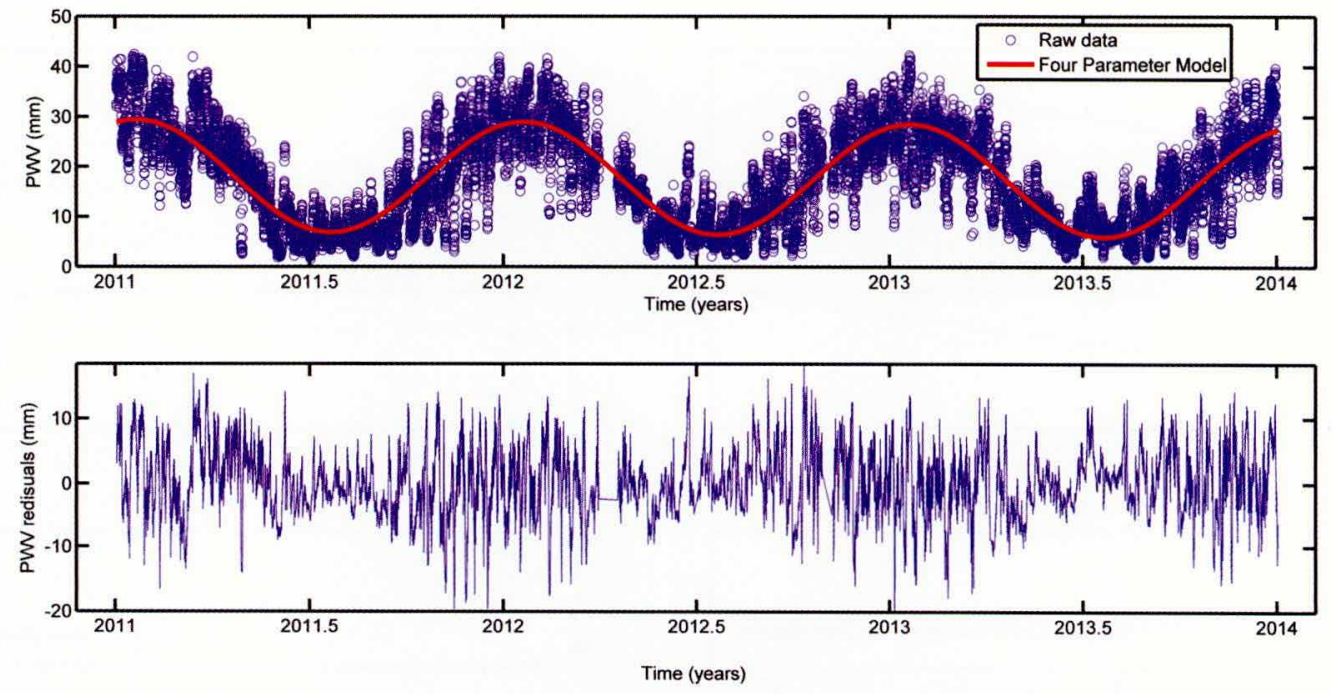

Figure 4. Time series of IPWV estimates for the GNSS station HRAO from ground based GPS receivers. The four parameter model fitted to the data yields a mean square error of $28.6 \mathrm{~mm}$ and the residuals indicate short term trends during summer and winter months.

carefully studying the multipath signals. In the study, it was illustrated that the signal strength received by the GNSS receiver can be correlated to the material that reflected the signal prior to being observed by the antenna. In this way, a type of material, or moisture content around the GNSS site, can be inferred.

\section{Integrated precipitable water vapour}

Water vapour is a dominant greenhouse gas (Kiehl and Trenberth, 1997). The GNSS space geodetic technique is utilized for remotely sensing atmospheric water vapour as small amounts of atmospheric water vapour affect the GNSS signal propagation velocity (Rocken et al., 1995). When GNSS microwave signals propagate the atmosphere, they are delayed by the Earth's ionosphere and the troposphere. The ionospheric delays can be removed from the dual frequency ( $L 1=1575.42$ $\mathrm{MHz}-\mathrm{L} 2=1227.60 \mathrm{MHz}$ ) observations and the tropospheric delay is estimated during the data processing steps (Bevis et al., 1992). The Zenith Wet Delay (ZWD) is related to the precipitable water vapour and temperature (Nilsson et al., 2013). Therefore, the ZWD is transformed to estimate IPWV as outlined by Bevis et al. (1994).

The general relationship between IPWV and temperature is that the amount of water vapour rises as the atmospheric temperature increases. This is due to the equilibrium vapour pressure of water increasing due to temperature increases; a state of $100 \%$ relative humidity occurs at the point when the partial pressure of water vapour is equal to the equilibrium vapour pressure (Soden et al., 2002). The IPWV values for the HartRAO GNSS station are plotted in Figure 4, processed in two-hour intervals for the period 2011 to 2013. The three depressions on the graph represent the winter months over the three-year period when the moisture levels in the atmosphere decrease. The summer months are represented by the peaks of the seasonal cycles and this is due to moisture increase in the atmosphere during rainy seasons. The four parameter model described by Gradinarsky et al. (2002) and Haas et al. (2003) is fitted to the data points to display this phenomenon. The linear trend fitted to the data indicates a decrease at a rate of $-1.2086 \mathrm{~mm} / \mathrm{yr}$.

These results have direct implications for understanding daily weather patterns and they can improve the current models that are used in meteorology. Furthermore, understanding atmospheric water vapour leads to a better understanding of climate change and the hydrological cycle as water vapour influences it (Duan et al., 1996; Allen and Ingram, 2002).

\section{Station position time series}

Time series plots (Figure 5) derived from processed GPS data, represent the positions in which a GPS station is moving in terms of north, east and height components over a specific time period. The positions on a time series plot could be affected by external factors such as the Earth-Moon interaction, which causes solid Earth tides (this is modelled by the analysis software), local movement of bedrock, local multipath (reflection of GPS signals off nearby reflective surfaces before reaching the receiver antenna, thereby erroneously increasing the apparent signal path length), groundwater variations (causing local crustal motion) and thermal noise of the GPS antenna (Dong et al., 2002). Apart from these factors, offsets can be introduced by a faulty instrument which is not working for a short period, anthropogenic effects and unfavourable environmental conditions (Williams, 2003). The factors mentioned, introduce biases or uncertainties in the quality of estimated parameters such as velocities and tropospheric zenith delays (Kenyeres and Bruyninx, 2004).

The height/up component in Figure 5 has the greatest noise relative to the North and East components; this is visible in the power spectrum plots of the components. This is expected from the time series data processed at HartRAO as Kenyeres and Bruyninx (2004) established that approximately $90 \%$ of the inconsistencies visible on time series plots appear in the height component. Time series plots are utilized 

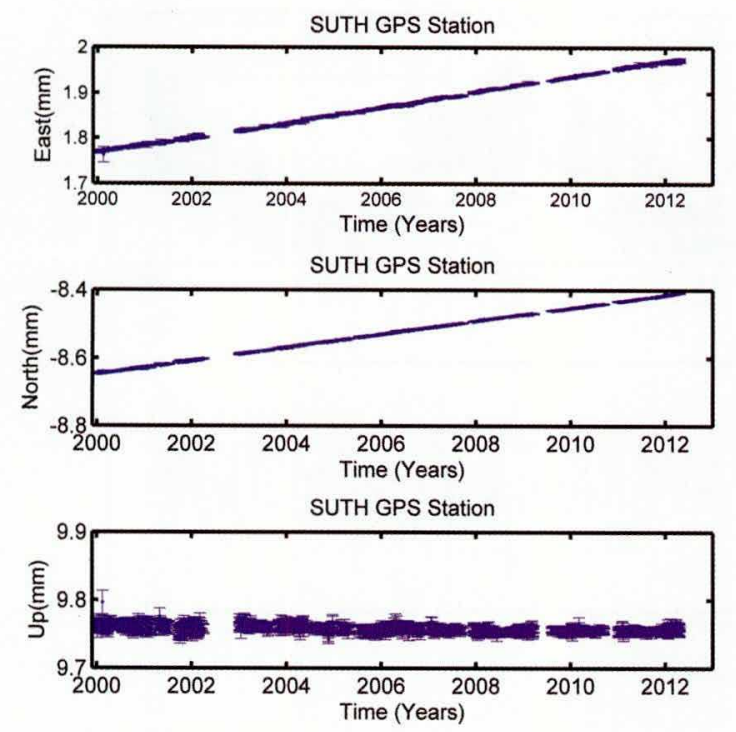
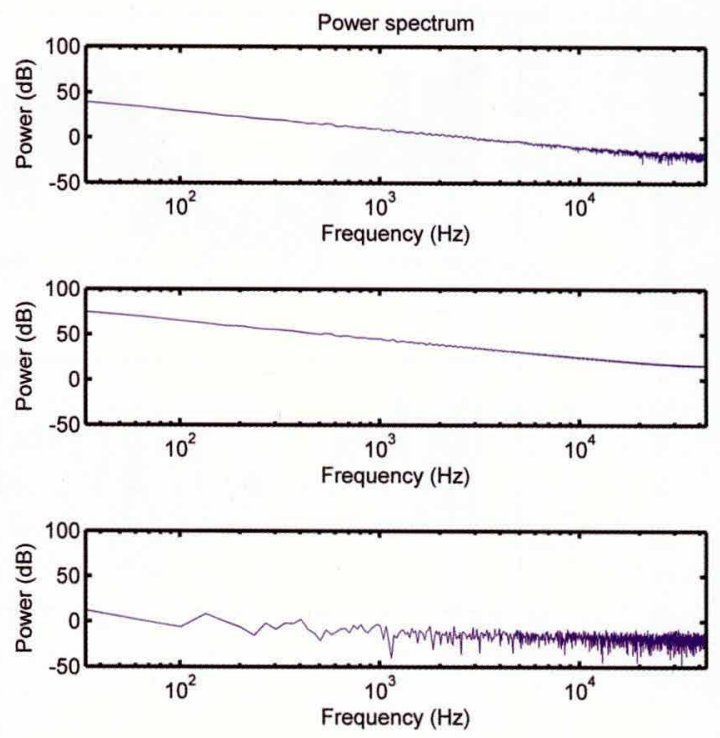

Figure 5. Time Series plot for the GNSS station SUTH for each component (North, East and Up) with their respective power spectrum.

when studying crustal deformation due to plate tectonics and other applications.

\section{GPS velocities}

The GPS technique is indispensable for deriving the velocities of surface points. These velocities are used in studying Earth phenomena such as plate kinematics, strain and estimating rheology properties (Hackl et al., 2011). The velocity data archived at HartRAO can be used for incorporation into global plate tectonics models such as NUVEL-1, NUVEL-1A and MORVEL (DeMets et al., 2010). Velocity vectors of some of the GNSS stations whose data are archived at HartRAO are displayed in Figure 6. The stations on the African plate move

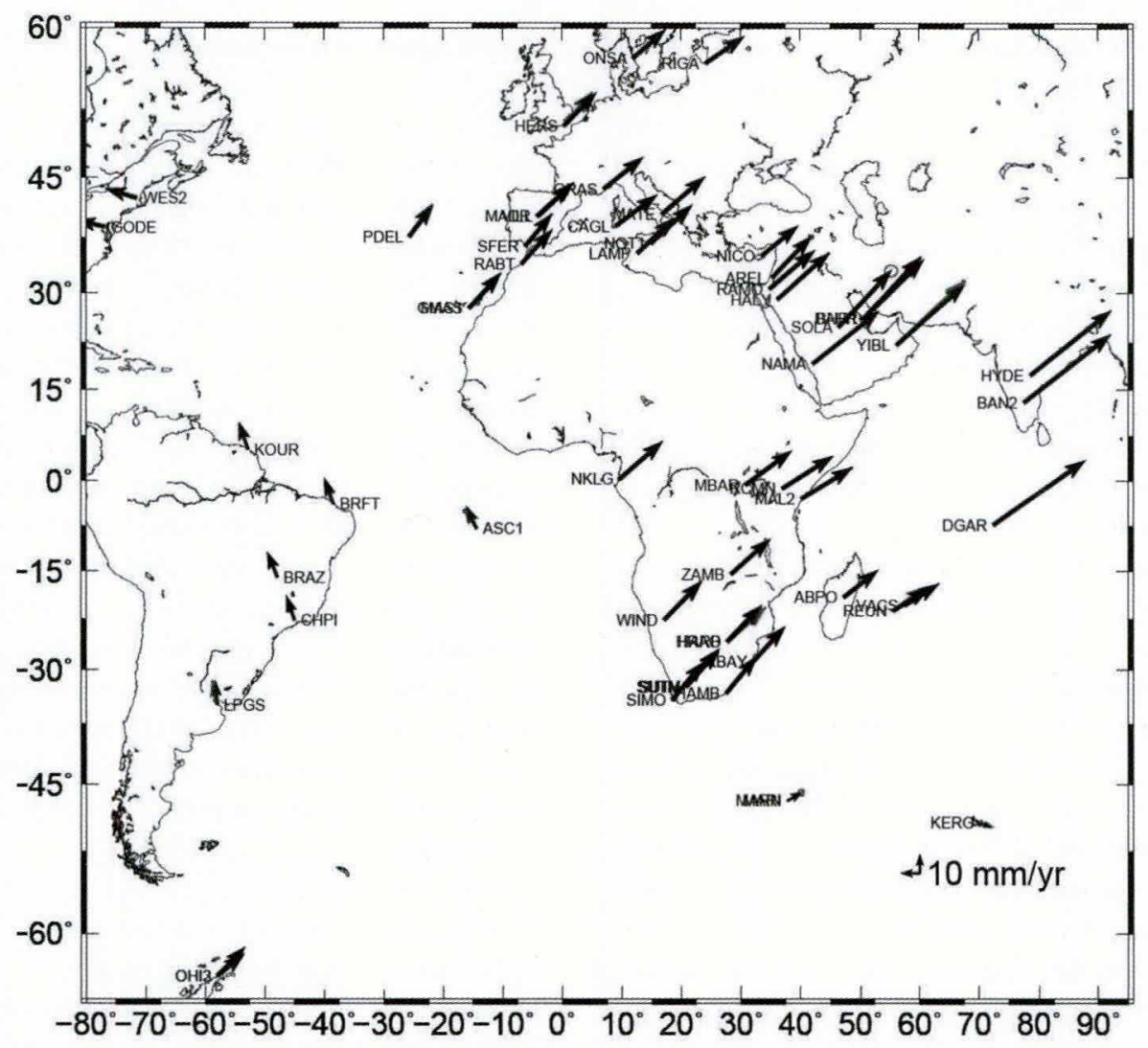

Figure 6. Velocity field vectors for some of the GNSS stations in the HartRAO data archive (Munghemezulu, 2013). 
slower than those of the South American plate and move in a different directions, as noted by DeMets et al. (1990).

\section{Contribution to unified-African geodetic reference frame (AFREF) project}

The HartRAO observatory participated towards the first computation of the AFREF static solution by utilizing GAMIT/GLOBK 10.2 software (Herring, 2002; King and Bock, 2000) to process GNSS data for the GPS weeks 1717 and 1718 which added South Africa's contribution. Different institutions namely: SEGAL (UBI/IDL), Portugal; Ardhi University, Tanzania and Director of Surveys and Mapping, Australia also participated by submitting an independent solution each, for combination by the French National Institute of Geographic and Forest Information (IGN). The combination was done by the IGN using the CATREF software (Altamimi et al., 2007). The AFREF project is aimed at establishing a unified African reference frame by utilizing GNSS as an observational technique, and this new reference frame must be consistent with the modern ITRF. Currently, different countries in Africa are using different reference frame systems (Rothacher, 2003) More information on the AFREF project can be obtained from Wonnacott (2005).

The combined preliminary results were presented at the Reference Frames for Applications in Geodetic Science (REFAG) meeting by Wonnacott et al., (2014). The solution computed by HartRAO indicates good agreement with the ITRF2008, see Table 1. A time series of Solution Independent Exchange (SINEX) files that contain station positions and velocities are freely available at ftp://geoid.hartrao.ac.za/sinex/.

\section{Preliminary web-based GNSS data management system}

An interactive web based map (Figure 7) was developed in CartoDB to make GNSS data products such as station position time series, quality check reports and sky plots available to users. Time series plots for the stations that HartRAO archives data for, that were not publicly available before, is now accessible to users. The users can access data quality reports and the sky plots. The GNSS data products derived from automated processing are accessible via links on the info windows which also have the picture of the GNSS station and information relating to the GNSS station such as the country, location and coordinates. The other GNSS data products such as velocities and IPWV values will be integrated into the system in future

An automated GNSS monitoring system was developed to allow the GNSS specialist based at HartRAO to monitor remote GNSS stations. This was necessary as the GNSS stations stream in data which gets processed to obtain the data products for

Table 1. Static solution statistics for HartRAO. The values are small indicating good agreement with ITRF2008.

\begin{tabular}{lcccr}
\hline & \multicolumn{4}{c}{ WRMS (mm) for HartRAO solution } \\
& E & N & UP & Stations \\
\hline GPS Week 1717 & 1.4 & 1 & 4.9 & 80 \\
GPS Week 1718 & 1.2 & 1.1 & 5 & 79 \\
\hline
\end{tabular}

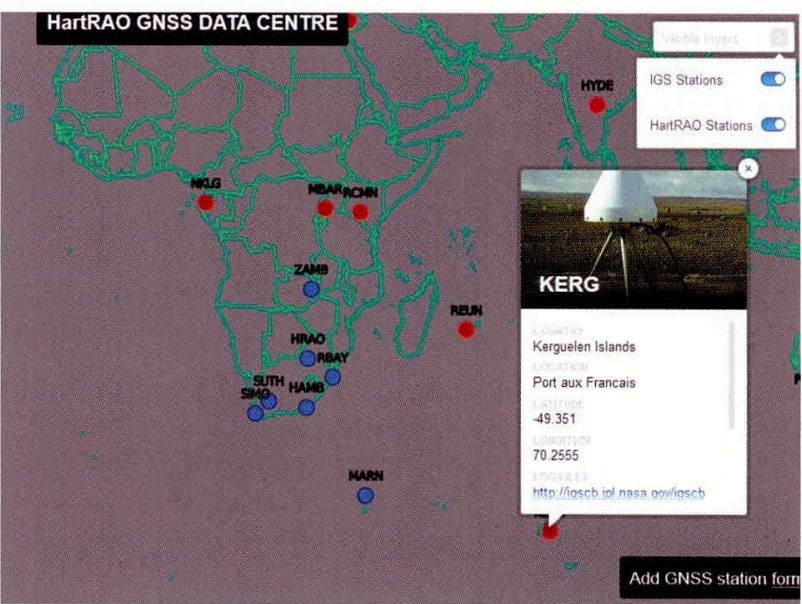

Figure 7. GPS data products are accessible to the end user via the interactive web based map (currently under development).

the interactive web based map. If there are connectivity problems preventing data from being acquired from a certain station, then, one will be able to see what time the problem occurred. The benefit of this is that problems can be fixed or people in charge of the remote station can be contacted. This helps to ensure that data delivery is not interrupted for prolonged periods. The monitoring system was created by utilizing a script that uses an internet link to log into a remote GNSS station to check if a station is working. The report generated is then automatically e-msailed to the GNSS specialist at HartRAO, this report can be accessed on any device which can access e-mails.

\section{Conclusions}

The HartRAO observatory hosts four collocated space geodetic techniques VLBI, SLR, DORIS and GNSS. Meanwhile, the LLR technique is still under development. A data management system was implemented for GNSS data. These data are important for monitoring natural phenomena such as plate tectonics, sea level changes and crustal deformation on a large scale. This interactive map forms a basis for the establishment of a space geodetic data centre at HartRAO. In future, this interactive map will be expanded to include all GNSS stations which HartRAO archives data for, and the IPWV values and velocities will be incorporated into the data management system. It is recommended that more GNSS stations be installed to improve the current network so that the GNSS data products, for example, velocity vectors can cover the area of interest more densely. Collaborations should be formed with other organizations to enable data exchange. This data management system should be implemented for other space geodetic techniques (i.e. VLBI, SLR and LLR).

\section{Acknowledgements}

The authors would like to acknowledge the Hartebeesthoek Radio Astronomy Observatory (HartRAO) and Inkaba yeAfrica for funding this research. We thank the Centre for Geoinformation Science at the University of Pretoria for their support. We are also grateful to Stoffel Fourie and an 
anonymous reviewer for suggestions to improve the manuscript. This is Inkaba yeAfrica contribution number 146.

\section{References}

Allen, M.R. and Ingram, W.J., 2002. Constraints on future changes in climate and the hydrological cycle. Nature, 419, 224-232.

Altamimi, Z., Sillard, P. and Boucher, C., 2007. CATREF software: Combination and Analysis of Terrestrial References. LAREG, Technical, Institut Géographique National, Paris, France. 26pp.

Argus, D.F. and Heflin, M.B., 1995. Plate motion and crustal deformation estimated with geodetic data from the GPS. Geophysical Research Letters, 22, 1973-1976.

Beutler, G., Moore, A.W. and Mueller, I.I., 2008. The International Global Navigation Satellite Systems (GNSS) Service: developments and achievements. Journal of Geodesy, 83, 297-307.

Bevis, M., Businger, S., Herring, T.A., Rocken, C., Anthes, R.A. and Ware, R.H., 1992. GPS meteorology: Remote sensing of the atmospheric water vapour using the Global Positioning System. Journal of Geophysical Research, 97, 15787-15801.

Bevis, M., Businger, S., Chiswell, S., Herring, T.A., Anthes, R.A., Rocken, C. and Ware, R.H., 1994. GPS Meteorology: Mapping Zenith Wet Delays onto Precipitable Water. Journal of Applied Meteorology, 33, 379-386.

Chew, C.C., Small, E.E., Larson, K.M. and Zavorotny, V.U., 2013. Effects of near-surface soil moisture on GPS SNR data: development of a retrieval algorithm for soil moisture. Geoscience and Remote Sensing, 52, 537-543.

Combrinck, L., 2014. Hartebeesthoek Radio Astronomy Observatory: Space Geodesy status and progress, Proceedings of the Second AfricaGEO Conference, CONSAS Conference, Cape Town, South Africa, 1-12.

Defraigne, P., Banerjee, P. and Lewandowski, W., 2007. Time transfer through GPS. Indian Journal of Radio and Space Physics, 36, 303-312.

DeMets, C., Gordon, R.G., Argus, D.F. and Stein, S., 1990. Current plate motions. Geophysical Journal International, 101, 425-478.

DeMets, C., Gordon, R.G. and Argus, D.F., 2010. Geologically current plate motions. Geophysical Journal International, 181, 1-80.

Dong, P., Fang, P., Bock, Y., Cheng, M.K. and Miyazaki, S., 2002. Anatomy of apparent seasonal variations from GPS-derived site position time series. Journal of Geophysical Research, 107, 1-17

Dow, J.M., Neilan, R.E. and Rizos, C., 2008. The International GNSS Service in a changing landscape of Global Navigation Satellite Systems. Journal of Geodesy, 83, 191-198.

Duan, J., Bevis, M., Fang, P., Bock, Y., Chiswell, S., Businger, S., Rocken, C. Solheim, F., van Hove, T., Ware, R., McClusky, S., Herring, T.A. and King, R.W., 1996. GPS Meteorology: Direct Estimation of the Absolute Value of Precipitable Water. Journal of Applied Meteorology, 35, 830-838.

El-Rabbany, A., 2002. Introduction to GPS: The Global Positioning System. Artech house, Norwood, United States of America, 176pp.

Estey, L.H. and Meertens, C.M., 1999, TEQC: The multipurpose toolkit for GPS/GLONASS data, GPS Solutions, 3, 42-49.

Estey, L. and Weir, S., 2014. Teqc Tutorial, Basics of Teqc use and teqc products. Available at http://www.unavco.org.

Gradinarsky, L.P., Johansson, J.M., Bouma, H.R., Schemeck, H.G. and Elgered, G., 2002. Climate monitoring using GPS. Physics and Chemistry of the Earth, 27, 335-340.

Haas, R., Elgered, G., Gradinarsky, L. and Joliansson, J., 2003. Assessing long term trends in the atmospheric water vapor content by combining data from VLBl, GPS, radiosondes and microwave radiometry. In: W. Schwegmann and V. Thorandt (Editors), Proceedings of the I6th Working Meeting on European VLBI for Geodesy and Astrometry, BundesamI fur Kartografie und Geoddsie. Leipzig / Frankfurt am Main, Berlin, Germany, 279-288.

Hackl, M., Malservisi, R., Hugentobler, U. and Wonnacott, R., 2011 Estimation of velocity uncertainties from GPS time series: Examples from the analysis of the South African TrigNet network. Journal of Geophysical Research, 116, 1-12.
Herring, T. A., 2002. GLOBK: Global Kalman Filter VLBI and GPS analysis program v 10.0, Massachusetts Institute of Technology, Cambridge, 98pp.

Herring, T.A., King, R.W. and McClusky, S.C., 2010. Introduction to GAMIT/GLOBK. Available at http://www-gpsg.mit.edu/ simon/gtgk/ Intro_GG.pdf.

Hofmann-Wellenhof, B., Lichtenegger, H. and Wasle, E., 2008. Global Navigation Satellite Systems: GPS, GLONASS, Galileo and more. Available at http://www2.pv.infn.it/ genova/gps/GpsGalileoGlonass.pdf.

Isioye, O.A., Combrinck, L., Botai, J.O. and Munghemezulu, C., 2015. The Potential for Observing African Weather with GNSS Remote Sensing. Advances in Meteorology, 2015, 1-16.

Kenyeres, A. and Bruyninx, C., 2004. EPN coordinate time series monitoring for reference frame maintenance. GPS Solutions, 8, 200-209.

Kiehl, J.T. and Trenberth, K.E., 1997. Earth's Annual Global Mean Energy Budget. Bulletin of the American Meteorological Society, 78, 197-208.

King, R.W. and Bock, Y., 2000. Documentation of the GAMIT GPS analysis software, Massachusetts Institute of Technology and Scripps Institute of Oceanography, Massachusetts, New England, 206pp.

Larson, K.M., Poland, M. and Miklius, A., 2010. Volcano monitoring using GPS: Developing data analysis strategies based on the June 2007 Kilauea Volcano intrusion and eruption. Journal of Geophysical Research, 115, 1-10.

Lechner, W. and Baumann, S., 2000. Global navigation satellite systems. Computers and Electronics in Agriculture, 25, 67-85.

Mayer, D., Böhm, J., Combrinck, L., Botai, J. and Böhm, S., 2014. Importance of the Hartebeesthoek Radio Astronomy Observatory for the VLBI network. Acta Geodaetica et Geophysica, 49, 313-325.

Munghemezulu, C., 2013. Determination of geodetic velocity field parameters for the African tectonic plate using the technique of Global Navigation Satellite Systems, MSc dissertation, University of Pretoria, Pretoria, South Africa, 207pp.

Nilsson, T., Böhm, J., Wijaya D., Tresch, A., Nafisi V. and Schuh, H., 2013. Path Delays in the Neutral Atmosphere. In: J. Böhm and H. Schuh, (Editors). Atmospheric Effects in Space Geodesy, Springer Berlin Heidelberg, Berlin, Heidelberg, 124-126.

O'Connor, M., Bell, T., Elkaim, G. and Parkinson, B., 1996. Automatic Steering of Farm Vehicles Using GPS. Precision Agriculture, 767-777.

Rocken, C., van Hove, T., Johnson, J., Solheim, F., Ware, R., Bevis, M., Chiswell, S. and Businger, S., 1995. GPS/STORM-GPS Sensing of Atmospheric Water Vapor for Meteorology. Journal of Atmospheric and Oceanic Technology, 12, 468-478.

Rothacher, M., 2003. Towards a rigorous combination of space geodetic techniques. Proceedings IERS Workshop on combination research and global geophysical fluids, 18-21 November 2002, Munich, Germany, 7-18.

Soden, B.J., Wetherald, R.T., Stenchikov, G.L. and Robock, A., 2002. Global cooling after the eruption of Mount Pinatubo: a test of climate feedback by water vapor. Science, $296,727-730$.

Someswar, G.M., Rao, T.P.S.C. and Chigurukota, D.R., 2013. Global Navigation Satellite Systems and Their Applications. International. Journal of Software and Web Sciences, 3, 17-23.

Williams, S.D.P., 2003. Offsets in Global Positioning System time series. Journal of Geophysical Research, 108, 1-13.

Wonnacott, R., 2005. AFREF: Background and Progress Towards a Unified Reference System for Africa. Presented at the FIG Working Week / GSDI8 Conference, 16-21 April 2005, Cairo, Egypt, 1-12.

Wonnacott, R., Altamimi, Z., Combrinck, L., Fernandes, R., Morgan, P., Munghemezulu, C., Saria, E. and Farah, H., 2014. The first AFREF static solution. Presented at the Reference Frames for Applications in Geodetic Science (REFAG) symposium, 13-17 October 2014, Luxembourg, 1-19. 
Copyright of South African Journal of Geology is the property of Geological Society of South Africa and its content may not be copied or emailed to multiple sites or posted to a listserv without the copyright holder's express written permission. However, users may print, download, or email articles for individual use. 